\title{
Diversity of Microorganisms Hosted by the Albanian Medicinal Plants and the Antimicrobial Effect of the Chemical Compounds Extracted by Them
}

\author{
E. Troja ${ }^{1}$, N. Dalanaj ${ }^{2}$, R. Ceci², R. Troja ${ }^{2}$, \\ V. Toska1 ${ }^{1}$ A. Mele ${ }^{2}$, A. Como ${ }^{2}$, A. Petre ${ }^{2}$ and D. Prifti ${ }^{2}$ \\ ${ }^{1}$ Faculty of Medicine, Department of Pharmacy, \\ ${ }^{2}$ Faculty of Natural Sciences, Department of Chemistry \\ $\mathcal{E}$ Department of Industrial Chemistry, \\ Albania
}

\section{Introduction}

Aromatic medicinal plants are a very important part of the Albanian biological diversity. They are distributed in natural habitats, with different characteristics of relief and climate and are considered also as an important national richness.

Medicinal plants are evaluated for:

- their interest related with the production of the essential oils;

- their medical and industrial importance;

- their efficiency in different therapies;

- the economical values.

Herbal medicinal plants and the traditional medicine derived from them, have been used by the Albanian ancients and the Mediterranean neighbours, to treat the digestive disorders, dermatitis, toothaches, headaches, infections of the urinary tract, to reduce the high levels of the cholesterol and other different uses.

Recently, the application of the modern techniques and technologies with the final objective the preparation of herbal teas and drugs, derived from the aromatic medicinal plants and their extracts, have increased the interest about their use as bio-products with a lot of benefits from their curative properties. The production of dietary supplements derived from the plants is realized in recent days, through the cooperation between pharmacologists, microbiologists, botanists and chemists. Their use by children, adults, elderly and groups with specific conditions, is clearly expressed by the correlation between the tradition and new approaches.

The research study here presented, is designed by taking into consideration the huge number of the medicinal plants cultivated in Albanian habitats and their positive role in 
human health. It is realized by a team of the specialists in Industrial Microbiology, Food Technology, Pharmacognosy and Physic Chemistry.

The study is focused mainly in the evaluation of the microorganisms hosted by the selected fresh and dried medicinal plants and the role, the organic chemical compounds of these plants play in the growth of the isolated and identified microbial populations. In the experimental plan there was involved the study of the impact of some aromatic additives in food products, to increase their safety and the shelf life. The obtained results are the important dates to continue in the same research scientific field.

\section{General considerations}

Aromatic medicinal plants grow in the whole area of Albania, on the sea level, hills and mountains.

The recent studies are focused in their curative role-herbal teas produced in the country \& imported and in the production of the essential oils. The dates about their endemic micro flora and added microorganisms are limited and actually their study is a very important issue of the experimental work. The presence of the microbial strains in these plants depends not only on the growing areas and their climate, but also by the chemical compounds in the anatomic parts of the plants and the relationships plant microorganisms and microorganisms between each other (hosted in the same plant). Research teams are cooperating on the above issues to profit by the common experiences. They have as target, the use of the benefits of the microbial world for the development of modern biotechnologies and for the enrichment of the microbiological Collections with important strains, in order to use them for the industrial enzymatic processes and for the production of bio molecules. The achievements through the common projects in the taxonomic studies of the yeasts and moulds, isolated from natural habitats, bear witness to the raw materials, products and wastes can serve as favourable Carbon sources, with low cost, for the development of the microbiological strains, as total micro flora and/or for the screening of the special strains. The importance of the microbiological control of the aromatic medicinal plants is related today with the consume also of the herbal teas ( mentioned above) and the use of the aromatic plants as natural antimicrobials and food additives, in order to improve the quality and safety of the different food products to improve their odour and test.

Albanian natural habitats are full of Mediterranean plants, which serve also as raw materials for several technological treatments. Microbiological control of the medicinal plants is still unknown completely, comparing with the full studies in chemical and medicinal aspects. The experience in the microbiological control of these plants shows the presence of mould resistant strains, even the plants are dried or heat treated ( termotolerant strains or the resistant strains by the low values of water activity - aw 0.3-0.4, corresponding the monomolecular stratum). These strains are taking part in the micro flora of herbal teas, dealing in the market dried, shredded, milled and packaged. Their total microbial charge can not be "endemic", because of the added microbial populations derived from the "packaging system" and those from the surrounding environment, when the opened packets are used for a long time. 
The experimental work here presented is a modest contribution in:

- the evaluation of the total microbial charge of the selected aromatic and medicinal plants of the Albania ( fresh and dried) as Matricaria camomilla, Laurus nobilis, Folium sennae, Thymus vulgaricus, Thymus serpilium, Thymus longicaulis, etc.;

- the exploration of the special microbial strains-yeasts and moulds with a very important role in the human health and biotechnology;

- the use of the taxonomic methods in order to make the identification of the isolated and purified strains derived from the selected plants, having as target the creation of a Collection of these microorganisms;

- the study of the relationship between plants and microorganisms;

- making into evidence the chemical compounds presented in some selected plants, used to obtain essential oils by effective techniques of the extraction;

- the evaluation of the role of some aromatic herbs, to reduce the total microbial charges in different food products, animal proteins and other products, to increase their safety and to improve the quality (some Ready to Eat food products);

- the study, after the microbiological control, of the morphological and physiological characteristics of the isolated strains, in order to evaluate the presence and the effect of the selected strains in the safety of the above products.

The experimental work was realised in a five years period, in the framework of the projects R\&D, financed by the Albanian Government and other projects of the bilateral cooperations with foreign Institutions. The scientific research was done in the Department of Industrial Chemistry, Section of Food Technology and Microbiology, Faculty of Natural Sciences in the University of Tirana, with the cooperation of the Departments of Chemistry and Pharmacy of the same University. The natural selected habitats were selected according to a detailed experimental plan, determining also the specific herbal plants, characteristic for the areas under the examination. These plants offer more possibilities for the isolation and identification of the typical microbiological strains. In the experimental plan were involved also products originated by the above plants as herbal teas prepared in Albania and some food products of the Albanian market, used to observe the effect of the herbal additives on the reduction of their total microbial charge.

\section{Materials and methods}

\subsection{Sampling}

Based on the objectives of the experimental studies, the sampling involved:

- $\quad$ Fresh endemic plants, grown in fields and in a highness about 700-900 m above the sea level, as Laurus nobilis, Rosa canina, Thymus vulgaris, Thymus longicaulis, Saturea montana, Matricaria camomila, Folium senae, etc. and some herbal teas originated by them . These plants were known and used by the Albanians, even when the technologies of the medicinal plants did not existed.

- Food products with a high distribution in the Albanian market, consumed by the Albanian populations. There were selected products with a high percentage of the animal proteins and a low percentage of triglycerides (anatomic parts of chickens of the Albanian farms). There were selected also the vegetable conserves ( ketch up, other simple \& composed tomato sauces and green sauces), used to improve the quality of 
food products-commodities, produced in a short time, with a low cost and preferred by the Albanian consumers.

The selection was based in analogue studies. According to them, chemical compounds (aromatic and medicinal compounds) of the above plants have a natural antimicrobial behaviour towards epiphyte and added microorganisms. They reduce and/or eliminate the total charges or specific strains in the same time with their effect to improve the taste, the odour and the quality of the products where they are used as food additives.

From the animal proteinic foods were selected the anatomic parts of the chickens - white meat and the skin. The white meat was selected, because there is a fast increasing of its consume on the global level. It is agreeable by the consumers and offers low energetic values. The skin was selected, because, for all the anatomic parts of the poultry, being in the market without special treatments, as packaging in vacuum, or in the controlled atmospheres, the skin is the host of the added microorganisms, which are not characteristic flora, but a contaminated micro flora for the above product. Thus, it has a potential negative impact in the safety of the whole food product and in the consumers protection. The skin is also the part with a direct contact with the surrounding environment and with the selected natural antimicrobials, also. There were selected from the vegetable foods, principally red sauces, ketch up and green sauces. Red tomato sauces are part of the Albanian daily food. They are prepared by the Albanian companies with classic and modern technologies. The Albanians find them in the market together with analogue imported products from Italy, Greece and other countries. The consumers prefer simple and composed sauces. Their daily use is related with the modern tendencies of the nutrition and their use as additives in pastes and macaroni, other global foods, or as additives in the portions of the fast food network (for example the global consume of the ketch up). Green sauces were known later by the Albanian consumers, except the traditional mixers of herbs, individually prepared for special food portions. Actually they are used by the consumers and liked by the market, because of the new tendencies of the nutrition, transferred from the neighbours (Italy is known all over the world for the preparation and the consume of the green sauces, example " pesto alla Genovese").

Microbiological studies of the research team were focused last years in principal food products, as cereals and their products, milk and dairy products, alcoholic \& non-alcoholic beverages and others.

Sauces were not part of these studies because they were only added in principal food products; they were termically treated and most of them were prepared with substances used for their preservation, as ascorbic acid. Actually they are more distributed in the food portions, more used than before and most of them are prepared without chemical substances for preservation, labeling as "bio"products. The importance of their microbiological control is related also with a long period of their use, (they often are preserved for a long period of time, not hermetically closed, in home refrigerators or in cold storages of fast food network). So, actually it should not be neglected their impact in the safety of the prepared foods and also the role of the herbal additives (herbal medicinal plants) in the composed sauces, to reduce their total microbial charge and to increase the confidence of the consumers towards their use as simple food, or as part of the other food products.

A detailed description about the three important groups of the selected samples, mentioned above, is as follows: 
The characteristics of some of the selected aromatic medicinal plants:

- Matricaria chamomilla- an annual plant distributed and grown near populated areas in Europe and Northwest Asia; it is considered as native plant of the above areas. It has a right stalk with ramifications on the upper part of it, with characteristic whiteyellowish flowers. Pharmacological effect is related with the presence of chemical compounds as bisabolol, camasulen, spathulenol, flavonoides, hydroxicoumarins, rhamnogalacturonanes, etc. These substances are responsible for the antibacterial effect of the plant in open wounds, the antimicrobial effect upon Staphylococcus and Candida, that caused skin diseases. One of the most important chemical compounds -camasulen, is well-known for its antirritant and antioxidant effect. Alfa-bisabolol is responsible for the gastrointestinal effect, while flavonoides are known for a very positive effect against cough and bronchial diseases.

- Cassia angustifolia (senna)- a plant of tropical and subtropical areas, native in Africa, America \& naturalized and more uses in Europe. It is a brush wood with double leafs, always green and with yellow flowers. It is commonly used as herbal laxative tea with an effect originated by the derivatives of anthracene -A, A1,B,C,D sennosides (anthraquinone glycosides), present in the plant together with naphthacene derivatives. It is used in the treatment of constipation, stimulated the intestinal peristalsis.

- Satureja montana - endemic plant of Europe and other geographic areas. It is grown in Albania as a perennial sub shrub with yellow flowers. It is the origin of the essential oils composed by p-cimene, linalool, carvacrol, thymol, myrcene, limonene, pinene, etc. The chemical composition is responsible not only for the aromatic effect of the respective essencial oil, but for the strong antibacterial effect, overall against G+ bacteria, as Staphylococcus aureus, Streptococcus pyogenes and Sarcina sp..

\subsubsection{Albanian aromatic medicinal plants as row materials for the production of the essential oils}

A part of the whole experimental work, here presented, is the study of the extraction of the essential oils from Thymus vulgaris L. (thyme), Thymus Longicaulis C Preisl.(creeping thyme) and Rosmarinus officinalis L (rosemary):

- Thymus vulgaris is a culinary and a medicinal herb, used in Mediterranean areas, in Albania also. It is used both fresh and dried to flavour meats, sauces and other food products, together with other vegetable ingredients. The essential oil of thymus contains a high percentage of the antiseptic substance, called thymol.

- $\quad$ Thymus Longicaulis C Preisl is an evergreen perennial plant with pink flowers in summer and small green pine scented leaves. Its hydrodistillated essential oil are considered with an antioxidant activity in beta-carotene/linoleic acid system.

- Rosmarinus officinalis $L$ is a woody, perennial herb with fragrant, evergreen leaves and part of the mint family. Mediterranean areas are familiar with it, using the leaves for the culinary purposes. Rosemary is rich with biologically active compounds, including antioxidants, such as carnosic acid and rosmarinic acid.

The selected samples were taken from the Department of Pharmacy (Pharmacognosy Scientific Laboratory) and certified wholesalers, responsable for the medicinal plants export activities. 


\subsubsection{The characteristics of the selected animal proteinic food products and respective antimicrobial additives}

During the experiments, there are used also clove essence and oregano in order to observe their effect towards epiphyte and added micro organisms in selected food products, overall to evaluate the antimicrobial effect of the herbal plants, more used in food industries and in the preparation of food portions. Oregano is considered as a herb with double effect - to improve the sensorial characteristics and to reduce the microbial charge. The use of both above substances was limited in the study of their effect regard to the microbial populations in food with animal proteins. For the future it is planed a detailed study related with their micro flora and the relationship endemic micro flora/chemical compounds. Antimicrobial effect of them was tested in selected poultry products, simply packaged, with a high distribution in the Albanian market- poultry farms of Korca, Patosi and Gjirokaster.

\subsubsection{The characteristics of the vegetable composed conserves, selected for the microbiological tests}

Sampling includes also red tomato sauces, ketch up and green sauces of the Albanian market. Microbiological study of these samples was realised referred the presence of laurel, thyme, oregano and basil as important ingredients of composed sauces. The selection of these conserves was made having as target the illustration of the antimicrobial effect of the above ingredients in composed food products. There are used basil sauces, Bolognese sauces-B, with thyme as ingredient; ketch-up's nominated with initials $S$ and $K$, with the natural herbs: laurel, basil and thyme, as ingredients. There were selected also green basil sauces "Pesto" G and T. The obtained results of the composed sauces were compared with the results of the simple sauces. (the above initials are used for the confidentiality of the trade-marks).

General characteristics of the above herb ingredients, studied for the moment only as additives, are as follows:

- Cloves- Syzygium aromaticum, are aromatic flower buds of a special tree, grown first in Indonesia and other Asiatic countries. Dried cloves are used recently in the cuisines of all the world. They are used, for their medicinally properties, principally in dentistry and to improve the peristalsis also. The active compound, eugenol, comprises high percentage of the essential oil, extracted from the cloves ( about 90\%).

- Oregano- Origanum vulgare is a simple specie of Origanum from the mint family. The plant is originated by Asia, Mediterranean areas and Balkan Peninsula. It is grown as a perennial herb in average temperatures, in a $\mathrm{pH}$ range between 6.0 and 8.0. Chemical compounds of the essence are carvacrol, thymol, limonene, pinene, p-cimene, cisocimene, linalool and others. Oregano has a powerful antiseptic effect and a high antioxidant effect because of the high content of the phenol acids and flavonoides. The antimicrobial effect is well-known against the microorganisms, contaminants of food products as Listeria monocytogenes.

- Basil- Ocimum basilicum, is a medicinal plant with sedative, antispastic, antimicrobial and anti irritant effects. Antiseptic properties are related principally with the chemical compounds of the essential oil, prepared by the basil leaves, which is considered as the main active compound of the plant. These chemical compounds are eugenol, methyleugenol, linalool and others. 
- Laurel-Laurus nobilis, is a shrub with green and glossy leaves. Its leaves are aromatic and are used fresh or dried, usually in Mediterranean food products. They are used also in aromatherapy and for curative purposes. The essential oil of laurel is very important and full of chemical compounds as cineole or eucalyptol, terpenes, sesquiterpenes, methyleugenol, and others.

- Thyme-Thymus vulgaris is described in details on the above paragraphs.

The structure of the experimental work, including the selected samples, was designed to point out the effects on a wide range of the herbal medicinal plants: as additives or ingredients in food industries, as safety and quality herbal teas and as producers of essential oils with very positive effects for the human being.

\subsection{Methods}

The applied methods of analysis are chosen, based on the structure of the experimental plan. They include both microbiological and analytical methods.

Microbiological control of samples was realised using the followed steps and methodology:

- Preparation of the samples applying all the rules for their preservation as time, temperature, packaging, etc..

- Application of the Method of the Limited Dilutions, in order to determine exactly the total charge of the micro organisms.

- The use of the selective media to determine the presence of bacteria (MPA-Meat Peptone Agar - growth medium), yeasts ( MA-Malt Agar, YEPD-Yeast Extract Peptone Dextrose, YED-Yeast Extract Dextrose- growth media), moulds (CAPEK and YEPD growth media). Streptomycin was added in the selective media of the moulds, in order to prevent the development of the bacteria strains.

- The determination of the number of the present micro organisms using the numeration methods - Petri dishes divided in sectors and/or numerations in whole Petri dishes using a digit all colonies counter.

- The use of the classic methods for the isolation (screening) and the identification of the special strains ( the case of Rhodotorula sp. grown in Malt Agar and Rose Bengalis-media).

- The use of the taxonomic tests ( morphological, physiological and technological tests) for the specific isolated strains of yeasts and moulds (Barnet and LodderEKreger van Rij).

- The classification of the moulds were made referring the cultural characteristics as the colour, the structure of the colonies and their knitting behind the Petri dishes.

\subsubsection{Methods for the extraction of the essential oils}

The obtaining of the essential oils from the selected medicinal plants was done using the new effective methods of the extraction. One of them, a very effective extraction method, is the use of fluids in critical conditions, for example $\mathrm{CO}_{2}$, based on the properties of pressurized effluents and in the specific characteristics of the above chemical compound. $\mathrm{CO}_{2}$ is a clean effluent, cheaper than others, nontoxic and very effective to obtain good percentages of extracts, eliminating or reducing the environmental pollution also.

There are used in the experimental work, here presented, classic methods (hydrodistillation) of extraction \& subcritical fluid extraction with $\mathrm{CO}_{2}$. 
There are realised the comparative studies between classic and modern methods of extraction, identifying also with chromatographic methods (Gas chromatography-mass spectrometry, GC-MS), the organic compounds with industrial and scientific importance, presented in the extracted essential oils.

The quantitative determination of essential oils was performed using a Clevenger apparatus, following methodologies from Italian Pharmacopeia and WHO (World Health Organization) manuals. Distillation apparatus was composed from the following elements : 1 ) heat system, able to offer and maintain a controlled optimal temperature; 2) glass flask; 3) distillation apparatus Clevenger type; 4) vertical refrigerator. All these elements were provided from the Departments of Pharmacy and Chemistry, University of Tirana. There were used 100g. plant materials for each distillation procedure.

The chosen round-bottom flask had a volume of $3000 \mathrm{ml}$, in which were added $1000 \mathrm{ml}$ water. Distillation time duration was planned to be 5 hours. It was added $1 \mathrm{ml}$ of organic solvent (hexane), in order to collect the essential oil. The solvent was chosen based on GC-MS analyses technique. The average distillation rate was monitored to be around $2-3 \mathrm{ml} / \mathrm{min}$.

The percentage of the obtained essential oil was determined using the formula :

$$
\% \text { of essential oil }(\mathrm{ml} / \text { gram })=\frac{100\left(\mathrm{~V}_{2}-\mathrm{V}_{1}\right)}{a}
$$

$\mathrm{V}_{2}$ - volume of the obtained essential oil + hexane (ml)

$\mathrm{V}_{1}$ - volume of the quantity of the added hexane $(\mathrm{ml})$

a - quantity of plant material distilled (g.)

During the experimental work were used also analytical methods based on the official methods of analysis to determine the physicochemical characteristics of the selected food products.

\section{Results and the discussion}

\subsection{Microbiological analysis of the fresh aromatic medicinal plants}

Microbiological analysis, to determine the total number of the microorganisms presented in the different anatomic parts of Rosa cannina, Satureja montana and Thymus longicaulis Presl. (roots, stalks, flowers and leaves) were realised, using selective media for each group of microorganisms. In general, there were observed an infinitive number of microorganisms in the first dilution. So, there were analysed the second, the third and the fourth dilutions, in order to see the dominant strains. There were observed a presence of the pigmented yeasts and different characteristic moulds. There were isolated, purified and identified the yeast strains of Rhodotorula sp.. There were observed also the strains of Aureobasidium and others, which are in the process of the preservation in selective media, having as target, making them part of the Collection of the isolated microorganisms. The identified moulds were principally Ascomycetes as Aspergillus niger, Aspergillus candidum, Aspergillus terreus, Penicillium rubrum, etc.; Phycomycetes as Mucor hiemalis and Rhizopus nigricans; Fungi imperfecti as Cladosporium sp., Alternaria sp., Trichoderma viride, Trichotecium roseum, 
Helminthosporium sp. and others. The same strains were observed during the repeated annual microbiological analysis of the fresh plants.

\subsection{Microbiological analysis of the herbal teas}

The determination of the presence of the micro organisms, bacteria, yeasts and moulds in herbal teas: laurel, chamomile, savory and senna is presented in the histogram of the Fig. 1 . The graphic is the function of the logarithm of the total numbers of the micro organisms by the type of the herbal tea. The results presented in the Fig.1 are summarised from the parallel microbial tests for the determination of the micro organisms in the second dilutions of the herbal selected teas. Bacteria were dominant, while yeasts and moulds were numerable. The determination of the total microbial charge was made not as a target of the experiments, but as an indispensability to observe the microbiological differences (epiphyte and added micro organisms) between herbs with different active components. According to this, the interpretation of each result is focused on the peculiarities of the herbal teas.

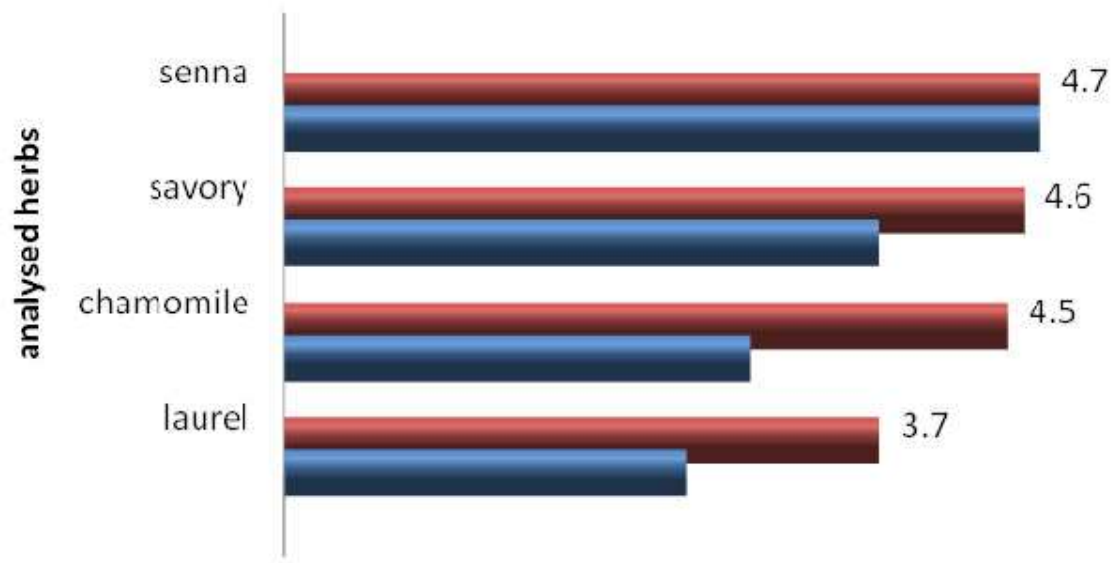

log. of the total number of microorganisms

Fig. 1. The evaluation of the total charge of microorganisms, present in the selected herbal teas

Laurel- laurel is a very good host for a big number of bacteria. Based on the experience of analogue studies, the total charge of bacteria is not related with epiphyte strains but with added strains in the dried laurel leaves with low values of the activity of water (dried leaves staying for a long time in open packets are hosts for different bacterial strains). The number of moulds in the selective media is high, but lower that total mould charge in the fresh leaves. This is related with the active components of the plant (moulds are grown also in a wide interval of values of the water activity). The number of the yeasts is practically 0 and it is related with the presence of alkaloids, which ( together with the low values of the activity of water) reduce drastically the number of the yeasts. Characteristic identified strains of the moulds are Aspergillus flavus, Aspergillus niger, Aspergillus tereus, Penicillium islandicum, Penicillium rubrum and Penicillium cyclopium. 
Chamomile - chamomile is the host of an infinite number of bacteria. There were identified using taxonomic methods, the added types of Pseudomonas sp. and Bacillus megatherium. There were not observed Staphylococcus and Candida. This is related with the repressive action of the plant on the above strains. The prevention of their growth is related with physic chemical conditions of the plant also. There was observed an average charge of moulds, which was not an indicator of the pollution, caused by added strains. PhycomycetesMucor sp.and Rhisopus nigricans were dominant.

Savory-making a distinction from other herbal teas, savory was host of the pigmented yeast, Rhodotorula sp. From the former experimental work related with the microbiology of the fresh plants, the same psychrotolerant strain was isolated in the fresh plant grown in low temperatures in mountains. The above specie is a mesophilic strain having as attribute the antioxidant properties, known and evaluated in the similar isolated strains, (Fig.3).

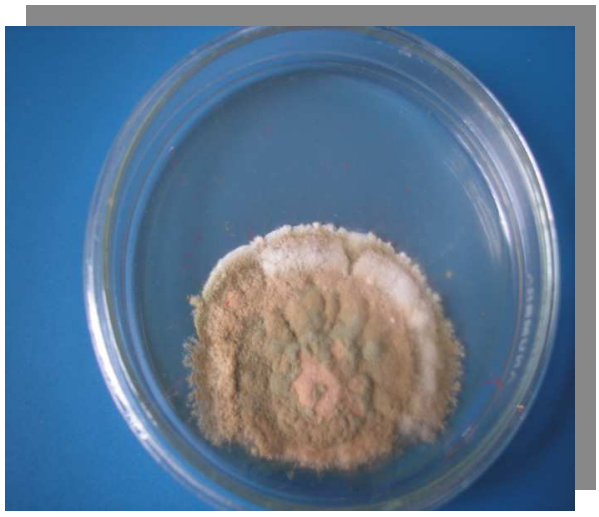

Fig. 2. Penicillium cyclopium in dried leaves of the laurel

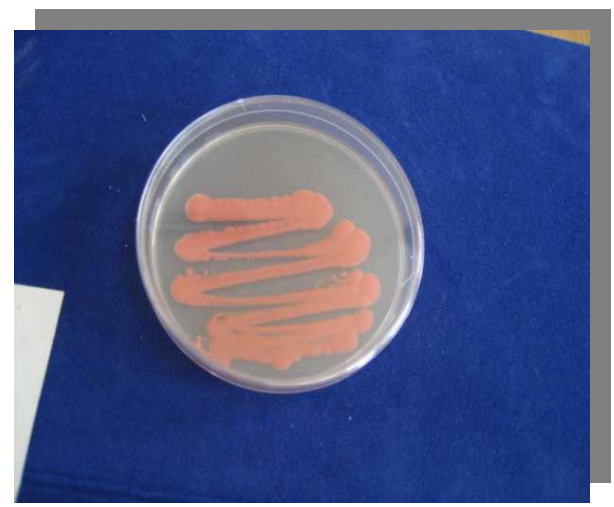

Fig. 3. Rhodotorula sp. isolated during the experimental work

Senna - there were observed some other specific mould strains hosted in senna dried leaves, Cladosporium sp. and Aureobasidium sp.. Based on the experience of the former experimental work with fresh plants as samples, Aurobasidium is attendant of the micro flora of the plants and other strains with antioxidant effect; while Cladosporium is epiphyte mesophilic strain of 
the areas with Mediterranean vegetation and is observed as a part of the micro flora of the respective earths.

\subsection{The extraction of the essential oils by the selected herbal plants and the study of their composition and properties}

The determination of essential oil content using fluid extraction in critical conditions (subcritical $\mathrm{CO}_{2}$ )

Plant materials from including thyme, creeping thyme and rosemary were extracted by liquid $\mathrm{CO}_{2}$, under liquid-vapour conditions near its critical conditions. The used apparatus is shown in Fig.4. The liquid $\mathrm{CO}_{2}$ extracts were compared with hydro distillates using GCMS. For each plant was observed and compared the presence of important chemical compounds in hydro distillates and $\mathrm{CO}_{2}$ extracts, analysing selectivity, differences and future objectives. The quantitatively determined yields of the $\mathrm{CO}_{2}$ extractions were 2.5 to 4.5 times larger than the yields of hydro distillations. For the extraction of the plant materials approximately 3-4 hours were needed and for the hydro distillation 5 hours. The yield of the extractions as function of time could be described with a simple equation.
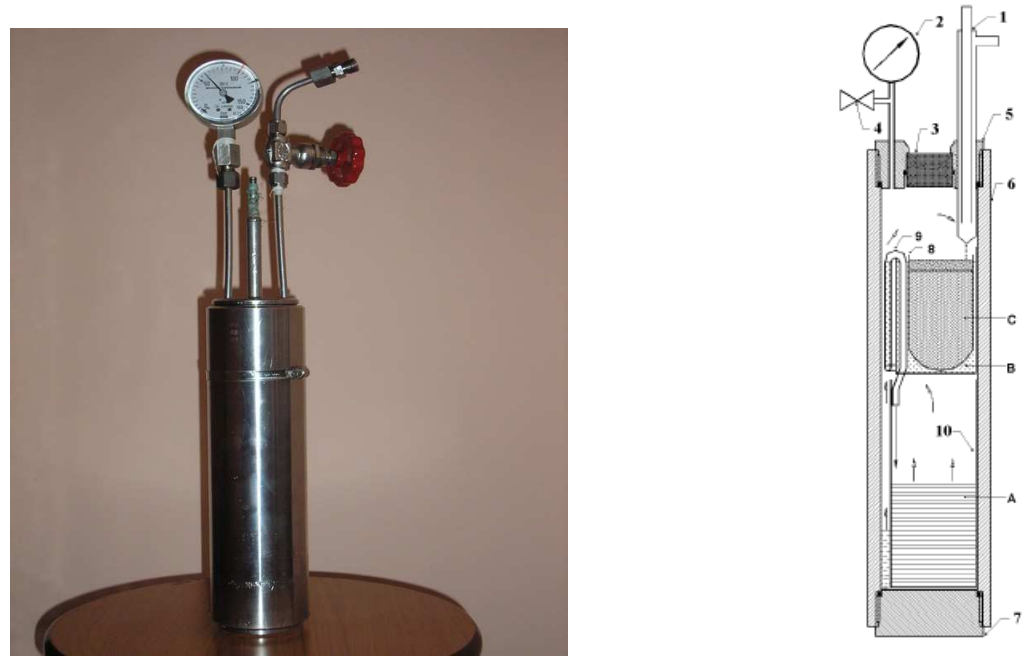

1) Cooling finger; 2) Pressure gauge; 3) Sapphire Window; 4) Valve; 5) Upper cover; 6) Steel Cylinder; 7) Bottom cover; 8) Extracting thimble; 9) Siphon; 10) Product dropping glass; A) Product; B) Extract solution; C) Plant material

Fig. 4. The equipment for the high pressure extraction with liquid $\mathrm{CO}_{2}$ under liquid - vapor equilibrium conditions.

The determination of the essential oil chemical composition with Gas chromatography Mass spectrometry (GC-MS)

The extracts obtained from hydro distillation and $\mathrm{CO}_{2}$ subcritical methods were analyzed using Gas chromatography-Mass spectrometry (Fig.5), based on standardized techniques, described in details as follows: 
Essential oil extracts were analyzed using a GC- 2010 (Shimadzu, Japan), equipped with a split/split less injector, electronic pressure control, AOC-20i auto injector, GCMS-QP2010 Plus mass spectrometer detector, and a GCMS Solution software.

The column used was a ZB-5 (Zebron) capillary column, 30m $\times 0.25 \mathrm{mmI}$.D. and 0.25_mphase thickness. Helium, $99.996 \%$ was used as a carrier gas at a flow of $1 \mathrm{~mL} / \mathrm{min}$. Oven temperature programming was $60{ }^{\circ} \mathrm{C}$ isothermal for $4 \mathrm{~min}$ then increased to $106{ }^{\circ} \mathrm{Cat} 2.5$ ${ }^{\circ} \mathrm{C} / \mathrm{min}$ and from $106{ }^{\circ} \mathrm{C}$ to $130{ }^{\circ} \mathrm{Cat} 1{ }^{\circ} \mathrm{C} / \mathrm{min}$ and finally from $130{ }^{\circ} \mathrm{C}$ to $250{ }^{\circ} \mathrm{C}$ at $20{ }^{\circ} \mathrm{C} / \mathrm{min}$, this temperature was kept constant for $10.2 \mathrm{~min}$. Sample injections (1_L) were performed in split mode (1:20).

The inlet pressure of the carrier gas was $57.5 \mathrm{KPa}$. Injector temperature was of $250{ }^{\circ} \mathrm{C}$ and MS ion source and interface temperatures were $230{ }^{\circ} \mathrm{C}$ and $280{ }^{\circ} \mathrm{C}$, respectively. The mass spectrometer was used in TIC mode, and samples were scanned from 40 to $500 \mathrm{amu}$. Thymol, borneol, camphor, eucalyptol and linalool were identified by the comparison with standard mass spectra, obtained in the same conditions and compared with the mass spectra from library Wiley 229. Rests of the compounds were identified by the comparison with the mass spectra from Wiley and Nils library.

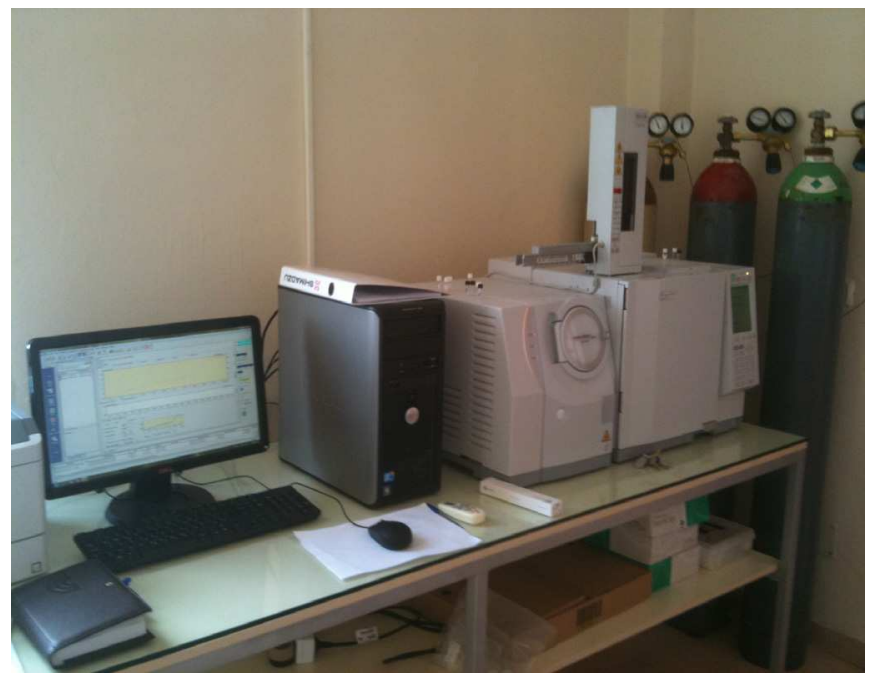

Fig. 5. GC - MS apparatus, used for the chemical composition analyses

The first step was the exact identification of the chemical compounds presented in thymus, creeping thymus and rosemary liquid essences. The above essences have been studied before but the methods, equipments and identification libraries used in this experimental work are modern and contemporary giving a high certainty for the chemical components and the whole essence.

There was confirmed by the obtained results, the predominant character of the phenolic structures in the liquid essences. The flavors and the distinguished antiseptic properties are related directly with the above components. Some of the principal chemical substances of 
Thymus vulgaris, Thymus longicaulis and Rosmarinus officinalis are: $\mathrm{a}$ - pinene, $\mathrm{p}$-cimene, camphor, 1,4 - terpineol, thymol, carvacrol, linalool, 1-8 cineol, limonene, camfene, $\beta$ myrcene, verbenone, cariophyllene and cariophyllene oxides. For the first time, during a long experimental work, was made possible the chemical analysis of the extracts taken by the use of subcritical $\mathrm{CO}_{2}$, in the liquid state with unique particularities. The information about the yield was enriched with the dates about the chemical content. The obtained results were very interesting. There was confirmed the idea that the $\mathrm{CO}_{2}$

extracts have another characteristics compared with those of hydro distillation. They are rich with new components, including terpene hydrocarbons and/or resins. Analyzing the extracts after the 21-st cycles, there is confirmed that the principal components, identified in the hydro distillation essence, are taken with very small differences using the $\mathrm{CO}_{2}$ subcritical method for the three aromatic selected plants. Observing the obtained chromatograms, analyzing also especially, the obtained fractions after a number of cycles (3, $9,15,21)$, it was confirmed a very interesting particularity related with two principal chemical substances, thymol and carvacrol. The extraction method with $\mathrm{CO}_{2}$ shows a preference and a specific affinity related with both components. They were extracted first (there were clearly observed their picks after the first three cycles); their extraction continued after 9 and 15 cycles, arriving in maximum values after the 21-st cycle. Their highness of the picks was considerable, with a clear difference from other components as phenols or terpene hydrocarbons. The above conclusion is very interesting, because of the confirmation of the specificities presented by the $\mathrm{CO}_{2}$ method of the extraction related with both most important chemical compounds of the studied herbal plants. These two components show their selective antimicrobial effectivity during the microbiological tests, including in the experimental work.

The above observation is fundamental and serves to stimulate the scientific research activities in the same issues. The short term objective is the work with pure reference standards of thymol, carvacrol and other chemical compounds, in order to make the quantitative evaluation of them, profited at the end of the work cycles, including also the final comparison with hydro distillation.

High total yilds of the extracts taken from the $\mathrm{CO}_{2}$ method and the specificity of it toward thymol and carvacrol, reinforce the idea that their quantity values may be higher that them on the liquid.

\subsection{Aromatic medicinal plants and their essential oils as antimicrobials in animal proteinic food products}

Medicinal plants, fresh and dried, together with the respective essential oils, produced by them in modern technological processes play a very important role to prevent the growth of the microbiological strains in food products. In the meantime they make the lyses of the existing cells, acting as the reducers of the presented strains. So, there is an antagonist relationship between bacteria, molds and yeasts and the active compounds of the plants or their essential oils, which explains the repressive effect of the specific active compounds toward different microbial strains. 
As it was mentioned above, there were selected the samples of white meat and poultry skin in order to explicate and evaluate the antagonist effects of some herbs and essential oils in animal products.

White meat and the skin of poultry products, selected directly on the market, were treated with oregano and with the essential oil of the cloves also, in order to improve the taste and to reduce the microbiological charges. The results are summarized in Fig. 6 and Fig.7. There are presented in the graphic of the Fig. 6 the total microbial charges of the three untreated skin samples from the Albanian farms (lp1, lp2, lp3) and the same treated samples with oregano $(\operatorname{lr} 1, \operatorname{lr} 2, \operatorname{lr} 3)$ \& with the essential oil of the cloves (le1, le2, le3). Referring to the corresponding results, there was observed a big number of bacteria comparing with the existence of the moulds and yeasts. This was an expected result, related with the amount of the triglycerides in the poultry skin, as well as with the environmental microbial contaminants which penetrate the simple packaging (without vacuum, without controlled or modified atmospheres). The reduction of the bacterial charges is evident and the effectivity of the action of eugenol was clear and really expected.

There are presented in the graphic of the Fig.7 the total microbial charges of the three untreated white meat samples from the Albanian farms (mp1, mp2, mp3) and the same treated samples with oregano $(\mathrm{mr} 1, \mathrm{mr} 2, \mathrm{mr} 3)$ \& with the essential oil of the cloves (me1, me2, me3).

The number of the bacterial strains in white meat samples was lower because of the lower content of the lipids; the tendencies of the microbial charge reductions under the action of oregano and eugenol were the same. Knowing the good practices of the production of the meat, the simple use of oregano is familiar principally for the red meat. There is planned for the future experimental work, the use of oregano essential , as a natural antimicrobial of red and white meat. The research team is working now to extract it from the fresh plant, using new techniques of the extraction.

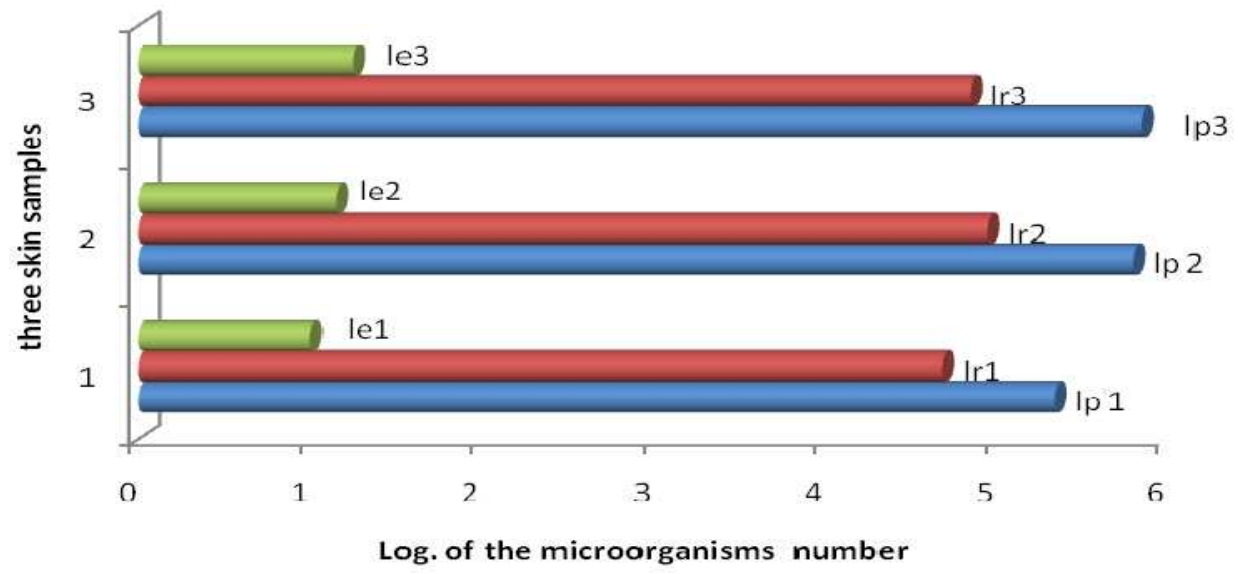

Fig. 6. The reduction of the number of microorganisms in poultry skins treated with oregano and the essential oil of the cloves 


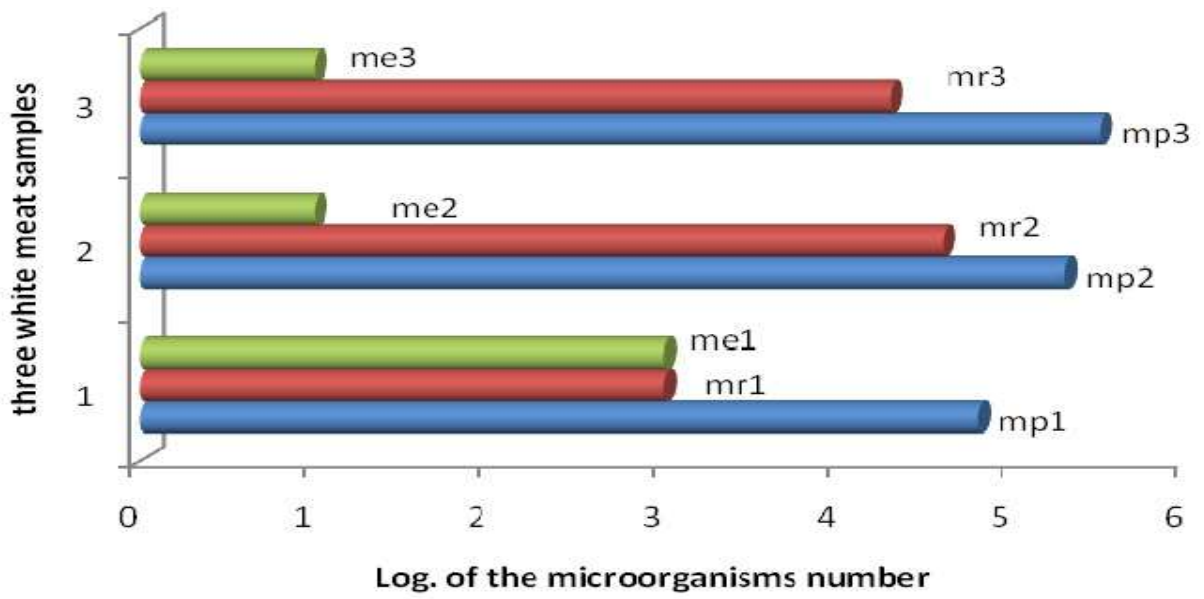

Fig. 7. The reduction of the number of microorganisms in poultry white meat samples treated with oregano and the essential oil of the cloves

\subsection{Aromatic plants as additives in different types of sauces}

Microbiological study of the some selected samples of sauces, was realised using two selected media MPA and YEPD-agar, to confirm the presence of the bacterial and mould charges. The summarized results are presented in the graphs below, Fig. 8 and Fig.9. The hermetically closed samples (S1, S2, S3, S4-red sauces; S5, S6- ketch up-s and S7, S8- green sauces of trade marks $G$ and $T$ ) were first analysed in order to veryfie the microbiological safety of the products and after, during the preservation period.

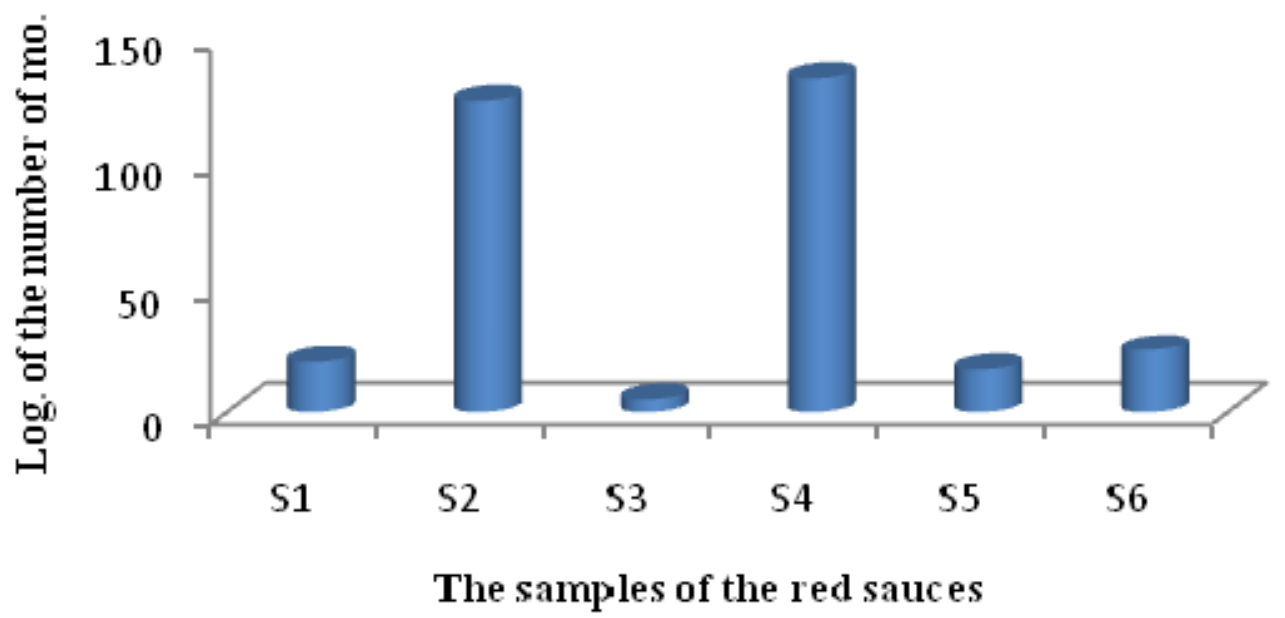

Fig. 8. The total microbial charge of the sauces samples 


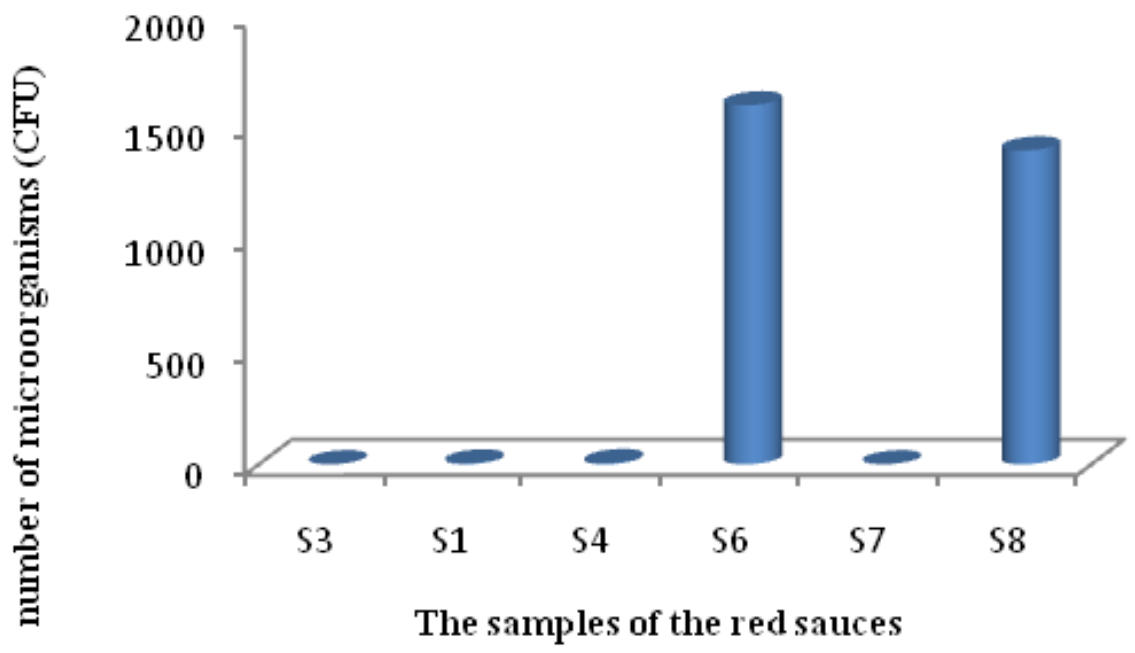

Fig. 9. The total number of the moulds in some of the sauces samples

The samples were identified by the initials and the detailed results were saved in order to respect the privacy of the trade marks. By the arithmetic mean results, taken by the parallel tests, in order to reduce the uncertainty of the measurements, there were observed the growth of some specific mould strains, presented in the not hermetically closed cans, even there were preserved in refrigerators. There is a quite difference between simple and composed sauces, with different herbs as ingredients. The above conclusion was achieved after many repeated microbiological tests of the same and analogue simple and composed samples.

S1 and S3 products were simple sauces with a relative low total charge, but with a high possibility to be increased, just after the opening. Sample S2 is a sauce with a high percentage of carbohydrates. This $C$ source is in favour of the growth of the added strains in the opened samples and usually a principal component of the selected liquid and solid nutrients A specific case is that of S4, a spicy one, where the pepper as ingredient, must be a powerful microbial charge reducer. Its effect really is decelerated by the presence of the animal proteins, part of the composed product. This proteins may be an appropriate medium for the growth of microorganisms. The antimicrobial effect of the active herbs, as ingredients, is obvious in S5 and S6 samples. S5 is a composed product, with a large amount of laurel and thyme, while S6 is prepared with basil and savory ingredients. The laurel of S6 acts against added microorganisms because of tannic substances and a small quantity of the eugenol as a chemical compound of its essential oil. Thus, the sample S6 resulted a safety product regarding to the total charge of microorganisms, preserved for a long time in low temperatures. The presence of the moulds were evident in the samples S6 and S8, while the added yeasts charge was practically 0 . The mould growth was related with a huge interval of the water activity (0.6-0.9), but also with the presence of basil as an added component in S6, S7 and S8. Concerning the bacterial strains in red sauces, the role of the chemical 
compounds of the aromatic plants to decrease the microbial charges was clear. Green concentrated sauces, rich on basil herb and other ingredients, were an appropriate substrate to stimulate the growth of the moulds. S7 sample was rich of a large amount of lactic acid and anacardic acid (6-pentadecylsalicylic acid), originated from some dried and woody fruits. That is why the green concentrated sauces offer a high resistance toward bacterial cells (example S7 with pine sticks and green herbs).

There are presented on the images of the Fig. 10 some specific identified microbial strains of the analysed samples.

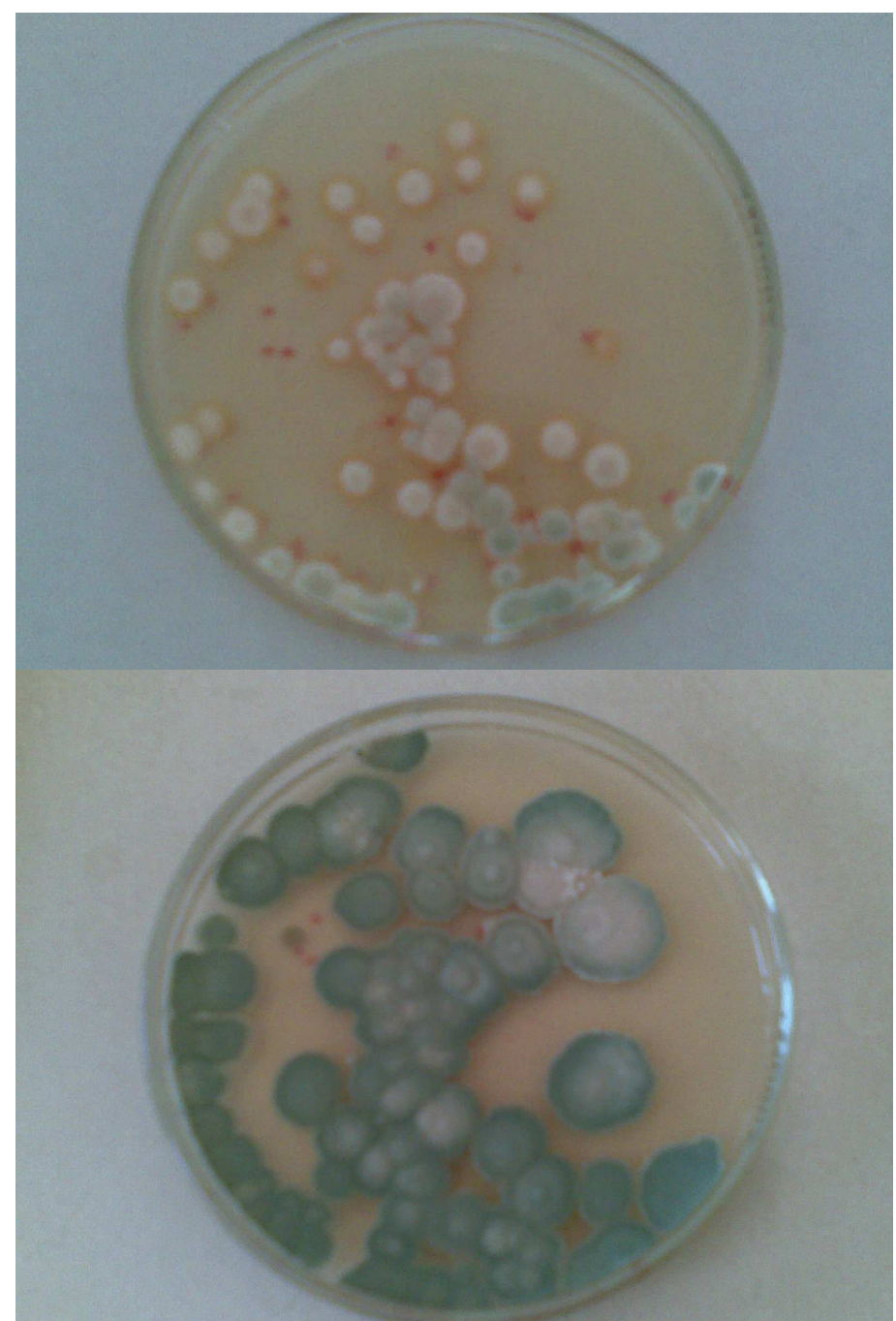

Fig. 10. Indentified moulds of the genus Penicillium ciclopum together with the bacterial pigmented strains, isolated by the composed sauces 


\section{Conclusions}

The anatomic parts, the structure of the cells and the chemical compounds of the aromatic medicinal plants can play a very important role in the growth and the development of the different microbial populations, which are hosted in the plants, food and pharmaceutical products derived from them, as native or added microflora.

The relationships between chemical substances and the microbial cells are antagonists, when most of these chemical components offer a powerful repressive action toward microbial cells, decelerating the growth and the reproducibility of the cells, or causing their lyses. Typical "poison" chemical substances are principally in the meantime "the active components" of the plants and their essential oils, tannins, alkaloids and other groups, specified on the text.

The development of the different genera of the plant microorganisms is related not only with the plant characteristics, but with the geographic vegetative areas where they are grown, the climate, the different plant varieties and with also, all the technological processing's of their transformation into final products, originated by herbal plants. The change of the above conditions is accompanied with big differences related to their presence and their morphology. Some of the microbial strains modify their behaviour, adopting their growth in new substrates, sporulating when they are sporeformings, reflecting obviously their new situation and their coexistence with other new strains.

The presence and the growth of the microorganisms are conditioned by the activity of water, temperature and the preservation time of the substrates.

Aromatic medicinal plants have shown specific properties related to their medical applications. Their use in obtaining of pure active ingredients or starting compounds (modified during chemical synthesis), in order to be part of effective new drugs, are some examples of their importance. Also, from another point of view, these natural plants can be considered as substrates for the development of the special microbial strains having extra and intracellular biomolecules as antibacterial and antioxidants, (the presence of $\beta$ carotenes in Rhodotorula genius and Aureobazidium genius, identified during the experimental work).

Essential oils, produced by the Albanian endemic and naturalised plants, act with their specific and significant active compounds, reducing the total charges of microorganisms, eliminating or preventing in the meantime the other strains and species.

Essential oils extracted from herbal plants, having also as target the optimization of their effects as antimicrobials in some food products, will be a future objective for advanced scientific researches on the same field.

The use of modern methods of extraction (critical fluid extraction) and new techniques for their chemical analysis (GCMS equipment), has offered the first results, related to the chemical compound of the extracted essential oils, making possible the study of the relationship between chemical compounds and identified strains.

The controlled tests related to the action of essential oils in food products and also the preventive action of fresh parts of the herbal plants, promise a future use of them in a wide 
range as antiseptic and antioxidant ingredients or additives of many food products, overall commodities. Their antimicrobial effect is accompanied together with the improvement of the sensorial properties of the food products. Referring to the experimental work, there were evaluated some tests with a very high reduction of the microbial survival, about $10-30 \%$ reduction.

In the future are planned new experiments, to optimize the effect of the extracted essential oils, towards composed, analogue food products.

The determination of the total number of the microorganisms in red and green sauces confirmed the predominance of mould strains and served also to enlarge and orient the experimental plan toward taxonomic studies for the identification purposes.

The comparison of the results between simple and composed sauces, rich with herbs, reflects an obvious reduction of the microbial pollution particularly in the presence of laurel, thymus and oregano. A high reduction is evident, compared also with simple sauces produced with chemical conservants. All the detailed interpretations of these results are given in specific paragraphs of the publication.

\section{References}

Asllani, U. (1992). “ Chemical Nature of the Albanian Essential Oils . Thier polychimism and thir quality improvement", Durres, Albania.

Barnet, H. L. \& Hunter, B. ( 1972). „Ilustrated genera of Imperfect Fungi““,Burgess Pub. Co , 3rd. edition, ISBN-10: 0808702661, Burgess Pub. Co.

Buzzini, P. (2000). "The rising power of yeasts in science and industry", Teenth International Symposium on Yeasts. 27 august-1 september 2000.

Buzzini, P. ( 1999). "Current Genetics" ( Eukaryotes with emphasion on: Yeasts, Fungi, Protists, Cell Organellas.) XIX International Conference on Yeasts Genetics and Molecular Biology, 25-30 May, Rimini, Italy.

Campbell, I.\& Duffus, J.H.(1988). "Yeast a practical approach" ; ISBN-13: 978-0947946807 Oxford University Press, USA.

Capelli, P.\& Vannuci, V. (2005). “Chimica degli alimenti. Conservazione e Transfomazione” 3rd edition, ISBN 8808075893, Italy.

Demiri, M. ( 1979). "Plant Determinant” SHBLU , Tirana, Albania.

Frashëri, M.; Prifti, D. (1997) " Practicum of Technical Microbiology”, Tirana, Albania.

Kurtzman, C.P. (2011)."The yeasts: a taxonomic study" 5 Edition, Publisher Elsevier, ISBN0123847087, 9780123847089

Mónica, R. Gonzalo, V. Guillermo, R. Fornari, T. (2011) "Fractionation of thyme (Thymus) vulgaris L.) by supercritical fluid extraction and Chromatography ", Journal of Supercritical Fluids 55, 949-954.

Hemalatha, S. Vivekananda, M. Yogesh, M. (2007)“Microwave Assisted Extraction - An Innovative and Promising Extraction Tool for Medicinal Plant Research", Pharmacognosy Reviews, Jan - May 2007. 
Sarikurkcu, C. Sabih, O.M. Tepe, B. Can, S. Mete, E. (2010)“Essential oil composition and antioxidant activity of Thymus longicaulis C Preisl, subsp. Longicaulis, var. longicaulis". Food. Chem. Toxicol. 48(7), Elsevier, April 2010.

Sima, Z. (1994). "Pharmacognosy", SHBLU, Tirana, Albania.

Tortora, G.J.; Funke B. R.; Case Ch. L.; (2010)“Microbiology- An introduction”, the Benjamin/Cummings Publishing Company, ISBN 0321550072.

WHO, (1999)“Monographs on selected medicinal plants”, Volume 2, Geneve . 


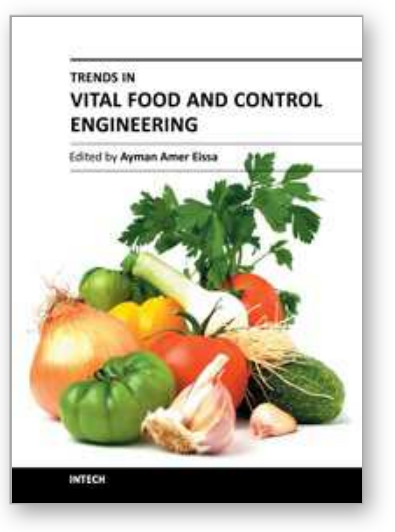

\author{
Trends in Vital Food and Control Engineering \\ Edited by Prof. Ayman Amer Eissa
}

ISBN 978-953-51-0449-0

Hard cover, 290 pages

Publisher InTech

Published online 05, April, 2012

Published in print edition April, 2012

This book is an example of a successful addition to the literature of bioengineering and processing control within the scientific world. The book is divided into twelve chapters covering: selected topics in food engineering, advances in food process engineering, food irradiation, food safety and quality, machine vision, control systems and economics processing. All chapters have been written by renowned professionals working in food engineering and related disciplines.

\title{
How to reference
}

In order to correctly reference this scholarly work, feel free to copy and paste the following:

E. Troja, N. Dalanaj, R. Ceci, R. Troja, V. Toska, A. Mele, A. Como, A. Petre and D. Prifti (2012). Diversity of Microorganisms Hosted by the Albanian Medicinal Plants and the Antimicrobial Effect of the Chemical Compounds Extracted by Them, Trends in Vital Food and Control Engineering, Prof. Ayman Amer Eissa (Ed.), ISBN: 978-953-51-0449-0, InTech, Available from: http://www.intechopen.com/books/trends-in-vital-food-andcontrol-engineering/diversity-of-microorganisms-hosted-by-the-albanian-medicinal-plants-and-theantimicrobial-effect-of-

\section{INTECH}

open science | open minds

\section{InTech Europe}

University Campus STeP Ri

Slavka Krautzeka 83/A

51000 Rijeka, Croatia

Phone: +385 (51) 770447

Fax: +385 (51) 686166

www.intechopen.com

\section{InTech China}

Unit 405, Office Block, Hotel Equatorial Shanghai

No.65, Yan An Road (West), Shanghai, 200040, China

中国上海市延安西路65号上海国际贵都大饭店办公楼 405 单元

Phone: +86-21-62489820

Fax: $+86-21-62489821$ 
(C) 2012 The Author(s). Licensee IntechOpen. This is an open access article distributed under the terms of the Creative Commons Attribution 3.0 License, which permits unrestricted use, distribution, and reproduction in any medium, provided the original work is properly cited. 